\title{
Pengembangan Butir Soal Literasi Kimia pada Materi Sistem Koloid Kelas XI IPA SMA/MA
}

\author{
Wirna Eliza $^{1}$, Eka Yusmaita ${ }^{2 *}$ \\ ${ }^{1)}$ Program Studi Pendidikan Kimia, FMIPA, Universitas Negeri Padang \\ 2) Jurusan Kimia, FMIPA, Universitas Negeri Padang \\ *ekayusmaita@fmipa.unp.ac.id
}

\begin{abstract}
This study aims to develop a chemical literacy instrument on colloidal system material that can be used to measure the literacy level of students. The research design on the development of this chemical literacy instrument uses the Model of Educational Reconstruction (MER). This research has several stages including content structure analysis (curriculum analysis, content analysis, context analysis, content validity by subject matter experts) and teaching and learning research (student interview investigation). The content validity test is carried out by five validators and the results will be analyzed by the Rasch model using the facet application. The results of this study indicate that the value of exact agreements is $88.9 \%$, while the value of the expected agreements is $89.6 \%$ so it can be said that the results of the examiner's assessment are not much different from the expected results of the assessment
\end{abstract}

Keywords : Chemical literacy instrument, Colloid system, MER, Rasch model

This is an open access article distributed under the Creative Commons 4.0 Attribution License, which permits unrestricted use, distribution, and reproduction in any medium, provided the original work is properly cited. $\odot 2021$ by author.

\section{PENDAHULUAN}

Asesmen Kompetensi Minimum (AKM) merupakan salah satu bagian dari Penilaian Asesmen Nasional (Rohim et al., 2021). AKM adalah penilaian kompetensi dasar yang dibutuhkan seluruh peserta didik sehingga mampu mengembangkan kemampuan diri dan terlibat dalam kegiatan positif di lingkungan masyarakat (Mendikbud, 2020). Tujuan dari AKM adalah untuk mengukur kemampuan literasi membaca dan literasi numerasi. Literasi merupakan kemampuan seseorang dalam meng olah dan memahami informasi dari proses membaca dan menulis.

Pembelajaran kimia bertujuan agar siswa mampu menguasai konsep-konsep kimia dan menggunakan metode ilmiah yang dilandasi sikap ilmiah untuk memecahkan masalah dalam kehidupan sehari-hari. Peningkatan kualitas pembelajaran kimia perlu dilaksanakan terus menerus untuk menyesuaikan perkembangan IPTEK. Kemampuan tersebut erat kaitannya dengan perkembangan pada abad 21 sehingga perlu adanya penguasaan kemampuan literasi oleh peserta didik agar mampu bersaing dengan perkembangan jaman (Aisah et al., 2021).

Saat ini dapat diamati bahwa sains dan teknologi berkembang dengan begitu pesat.
Pendidikan dituntut untuk mampu menciptakan generasi muda dengan kemampuan yang luar biasa dalam menyelesaikan tantangan di kehidup an (Yuliati, 2017). Perubahan dalam bidang pendidikan merupakan sesuatu hal yang sangat esesnsial dalam mempersiapkan diri agar bisa beradaptasi dengan perkembangan zaman (Wijaya et al., 2016). Salah satu caranya dengan Penyelanggaraan pendidikan yang lebih adaptif (Afandi et al., 2016). Kemampuan literasi sains sangat penting untuk dimiliki masyarakat sehingga mampu menerapkan pengetahuan mengenai sains dan teknologi untuk pemecahan masalah di kehidupan nyata (Rahayu, 2017)

Literasi sains dapat dijabarkan sebagai kecakapan dalam menggunakan pengetahuan sains, mengenali pertanyaan, dan mengambil kesimpulan berdasarkan bukti-bukti, yang bertu juan untuk memahami dan menciptakan keputus an terkait dengan alam melalui aktivitas yang dilakukan manusia (Firman, 2007). Seseorang dengan kemampuan literasi sains yang baik akan melibatkan pertimbangan-pertimbangan sains dalam membuat keputusan (Yuliati, 2017). Hal yang paling utama agar dapat menumbuhkan kemampuan literasi sains siswa adalah bukan hanya pada proses pembelajaran tetapi juga adanya penerapan dari ilmu pengetauan yang 
dikuasai siswa untuk memecahkan permasalahan di lingkungan (Sani, 2014)

PISA merupakan program penilaian inter nasional yang menilai kemampuan literasi sains peserta didik. Program ini diselenggarakan seti ap tiga tahun sekali oleh OECD (Organization for economic cooperation and development). Berdasarkan hasil studi PISA 2018 Indonesia berada pada peringkat 70 dari 78 negara parti sipan. Dari hasil ini dapat disimpulkan bahwa kemampuan literasi peserta didik Indonesia tergolong cukup rendah (Sutrisna, 2021). Pengembangan kemampuan literasi sains yang kurang baik dalam proses pembelajaran menjadi salah satu penyebab rendahnya literasi sains peserta didik dan belum menjadikan PISA sebagai acuan dalam proses evaluasi pembela jaran di sekolah (Astuti et al., 2017).

Salah satu bagian dari literasi sains adalah literasi kimia (Shwartz et al., 2006). Literasi kimia dapat dijelaskan sebagai pemahaman terhadap sifat partikel materi, reaksi kimia, hukum dan teori kimia, serta aplikasi kimia dalam fenomena alam di lingkungan sehari-hari (Fahmina, Imansari et al., 2018). Seseorang yang memiliki kemampuan literasi kimia yang baik dapat menjelaskan peristiwa ilmiah yang berpedoman pada konsep kimia, menyelesaikan permasalahan berdasarkan ilmu kimia yang telah dipahami, serta dapat mengerti dan menggunakan penerapan kimia dalam kehidupan sehari-hari (Fahmina et al., 2019).

Ilmu kimia membantu peserta didik dalam memahami fenomena ilmiah di alam sekitar (Thummathong \& Thathong, 2018). Sistem koloid merupakan salah satu materi dari pelajaran kimia. Materi sistem koloid berperan penting dalam aktivitas sehari-hari diantaranya dalam bidang bidang farmasi, bidang industri, bidang pangan, dan pertanian. Selain itu, terdapat beberapa fenomena alam berupa penghamburan cahaya oleh partikel-partikel koloid atau disebut dengan efek tyndall dan proses penjernihan air yang menerapkan sifat-sifat koloid berupa adsorpsi dan koagulasi (Rahardiana et al., 2015). Oleh karena itu, dengan mempelajari sistem koloid yang berkaitan erat dengan kehidupan sehari-hari diharapkan mampu meningkatkan kemampuan literasi kimia peserta didik.

Penelitian mengenai pengembangan dan analisis instrumen literasi kimia telah banyak dilakukan di Indonesia. Penelitian yang dilaku kan oleh Muntholib (2018) tentang Development of simple multiple-choice diagnos tic test of acid- base concepts to identify students' alternative conceptions. Penelitian yang dilakukan oleh Thummathong (2016) tentang Construction of a chemical literacy test for engineering students. Selain itu, penelitian mengenai instrument literasi kimia juga sudah dilakukan oleh Arabbani (2019) dengan judul analysis the quality of instrument for measuring chemical literacy abilities of high school student using rasch model. Penelitian yang dilakukan oleh Satya \& Endang W. (2018) mengenai development and validation of an integrated assessment for measuring critical thinking and chemical literacy in chemical equilibrium. Berdasarkan penelitian tersebut ketersediaan penilaian yang tepat sangat diperlukan dalam pembelajaran kimia salah satunya adalah instrumen penilaian literasi kimia (Muntholib et al., 2018).

Penilaian terhadap kemampuan literasi kimia sangat diperlukan untuk mendukung pembelajaran yang lebih bermakna dan penting untuk menentukan tingkat pencapaian pemaham an peserta didik terhadap pembelajaran kimia dan aplikasinya dalam kehidupan (Arabbani et al., 2019). Oleh karena itu, instrument literasi kimia dibutuhkan agar dapat melatih kemampuan literasi kimia peserta didik. Terciptanya instru ment literasi kimia yang valid dan reliabel diharapkan dapat literasi peserta didik dalam menjawab soal (Pakesa \& Yusmaita, 2019).

Penelitian yang dilakukan oleh Arabbani (2019) dan penelitian oleh Satya dan Endang (2018) dapat dilihat bahwa instrumen tes yang mereka buat belum mampu mengukur masingmasing level literasi kimia (scientific, nominal, functional, conceptual, and multidimensional literacy) di dalam satu item butir soal, melainkan instrumen tes yang dibuat hanya mampu mengukur satu level literasi kimia dengan satu item butir. Selain itu instrumen tes yang mereka buat masih belum menerapkan dua atau tiga dari empat domain literasi kimia menurut Shwartz (konten, konteks, HOLS, dan sikap) dalam satu item butir soal. Oleh karena itu, dengan tercip tanya instrumen tes literasi kimia diharapkan dapat menggambarkan profil kesulitan peserta didik dalam menjawab soal pokok uji literasi kimia dan dapat mengukur sejauh mana pemahaman peserta didik terhadap konsep kimia, permasalahan kimia dan penerapannya dalam kehidupan (Yusmaita \& Nasra, 2017)

Instrument penilaian yang dikembangkan harus memiliki bukti validitas, reabilitas, tingkat kesukaran dan daya pembeda item butir soal 
untuk menggambarkan kualitas butir soal (Son, 2019). Salah satu model pengukuran yang dapat menganalisis kualitas instrument penilaian adalah model rasch. Model rasch merupakan salah satu model pengukuran satu parameter logistik (Rusilowati, 2018). Model rasch ini merupakan satu model analisis dari teori respon butir (Item Response Theory, IRT). Keunggulan model rasch adalah dapat mengidentifikasi respon error, mengidentifikasi skor data hilang, abilitas tidak hanya bergantung pada jawaban benar, dan dapat mengidentifikasi respon tebakan (Sumintono \& Widhiarso, 2014).

Perancangan instrumen literasi kimia pada penelitian berdasarkan aspek konten, konteks, High Order Learning Skill (HOLS), dan sikap (afektif). Keempat aspek tersebut merupakan aspek literasi kimia yang dikemukakan oleh Shwartz (Shwartz et al., 2006). Selain itu, juga terdapat rubrik instrument literasi kimia yang dikemukakan oleh Bybee berdasarkan level literasi sains diantaranya adalah scientific illiteracy, nominal scientific literacy, functional scientific literacy, conceptual scientific literacy, dan multi-dimensional scientific (Bybee, 1997). Instrumen literasi kimia pada sistem materi koloid ini diharapkan dapat mengukur dan menggambarkan kemampuan literasi kimia pada peserta didik dalam materi sistem koloid.

Butir soal literasi kimia ini disusun dengan mengkombinasikan dua kerangka berpikir, yaitu: 1). aspek- aspek literasi kimia berupa aspek konten, konteks, keterampilan belajar tingkat tinggi, dan sikap berdasarkan domain literasi kimia dan 2). rubrik penilaian berdasarkan level literasi sains. Instrumen tes literasi kimia diharapkan mampu menggambarkan kesulitan peserta didik dalam menjawab soal literasi kimia, dan mengukur tingkat pemahaman peserta didik terhadap konsep kimia dan aplikasi ilmu kimia dalam kehidupan sehari-hari. Dengan terciptanya butir soal literasi kimia yang valid dan reliabel diharapkan mampu digunakan sebagai alat eva luasi pembelajaran kimia dan dapat menggam barkan kemampuan literasi kimia peserta didik dalam menjawab soal tersebut.

\section{METODE PENELITIAN}

Penelitian ini merupakan jenis penelitian pengembangan dengan desain penelitian meng gunakan Model of Educational Reconstrucion
(MER) atau disebut juga sebagai model rekonstruksi pendidikan. MER terdiri dari tiga komponen yaitu: 1) Klarifikasi dan analisis konten sains (Clarification and analysis of science content), 2) Penelitian mengajar dan belajar (Research on teaching \& learning), dan 3) Pengembangan dan evaluasi pembelajaran (Design and evaluation of teaching and learning environment). Ketiga komponen tersebut saling berkaitan dan membentuk alur yang sistematik. Penjabarannya dapat dilihat pada Gambar 1. (Duit et al., 2012).

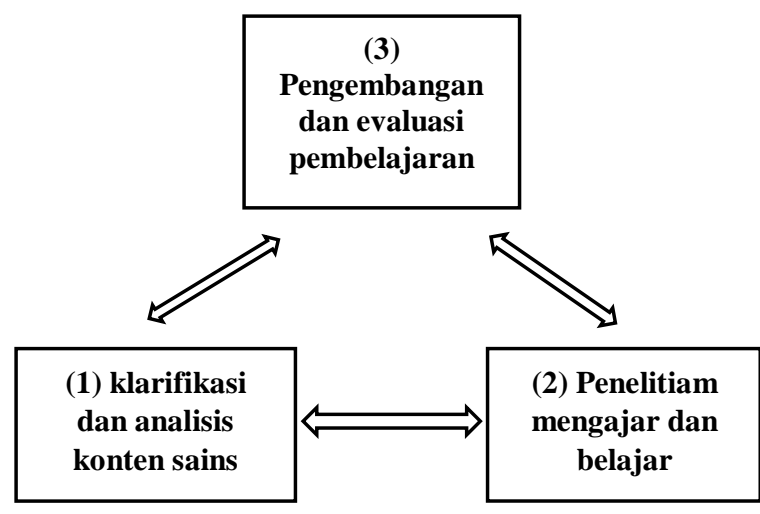

Gambar 1. Tiga Komponen Model of Reconstruction (MER)

Dalam pelaksanaannya, tahapan pada penelitian MER tidak mutlak harus menyele saikan tahapan pertama terlebih dahulu, melainkan setiap tahapan dapat dilakukan secara bolak-balik sehingga ketiga komponennya saling mempengaruhi. Ketiga komponen dilakukan berselang-seling sesuai dengan tujuan dan sesuai berdasarkan kepentingan penelitian yang ingin dicapai (Yusmaita \& Nasra, 2017).

Pada pelaksanaan penelitian ini dilakukan dua tahapan dari tiga tahapan mendasar pada MER. Tahapan pertama adalah analisis struktur konten yang meliputi analisis kurikulum, analisis struktur konten, dan analisis konteks serta validitas konten oleh subject matter expert. Tahap kedua yaitu penelitian belajar dan mengajar berupa investigasi wawancara peserta didik. Pelaksanaan penelitian ini, kedua tahapan model MER dimodifikasi menjadi skema baru. Informasi ini dapat dilihat pada Gambar 2. 


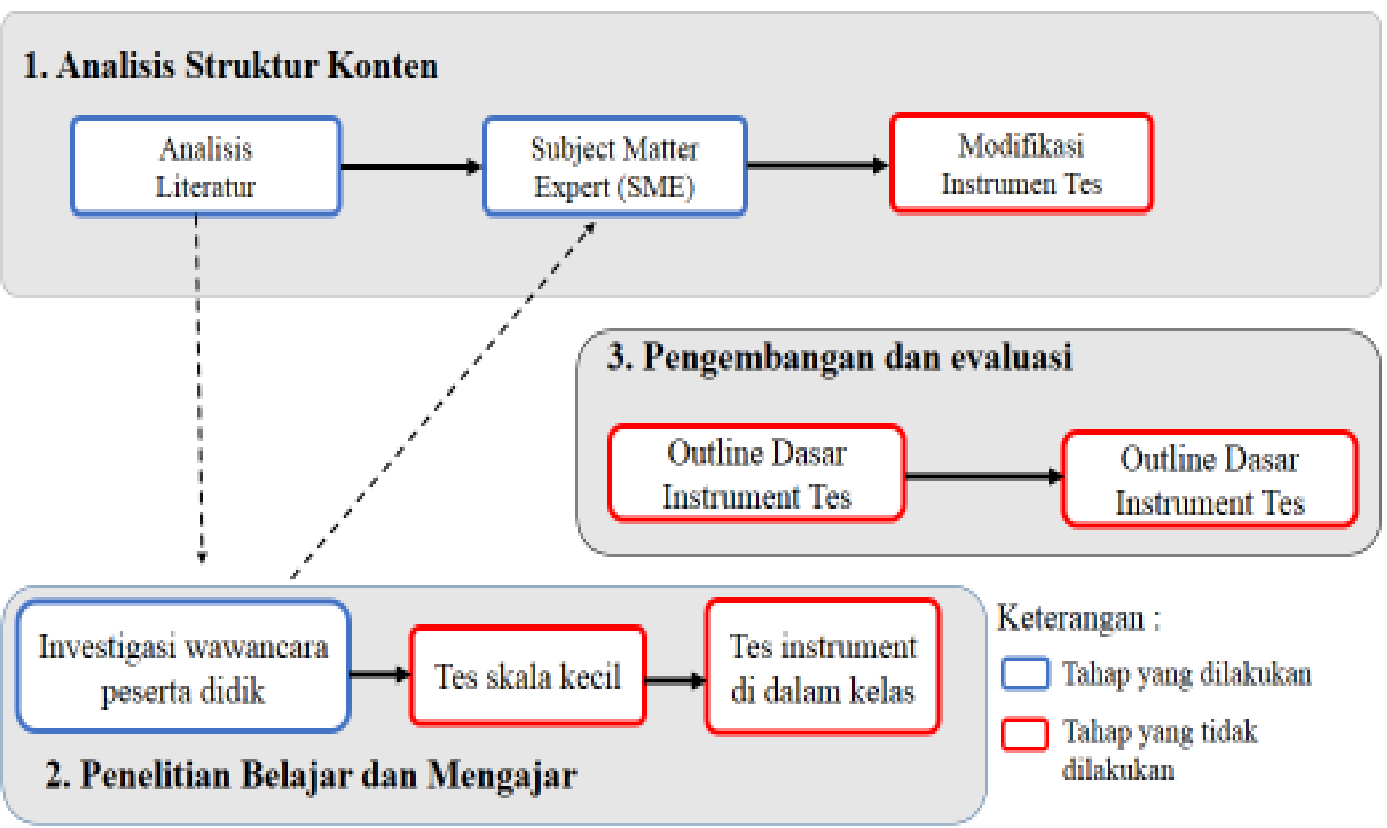

Gambar 2. Skema Bagan MER yang Dimodifikasi

Validitas diartikan sebagai tingkat ketepatan dan kecermatan suatu instrument tes dalam mela kukan fungsinya pada pengukuran (Matondang, 2009). Dalam penelitian ini dilakukan validitas konten yang merupakan kejituan suatu instru ment tes yang dilihat dari segi isinya (Latisma, 2011). Uji validitas konten dalam penelitian ini dilakukan oleh 3 orang dosen kimia FMIPA UNP dan 2 orang guru kimia di SMA. Instrumen penelitian yang digunakan adalah lembar validasi konten soal literasi kimia yang telah dirancang dan akan dinilai oleh lima orang validatro tersebut. Penilaian dilakukan dengan memberi kan penilaian dengan rating 1-3 dengan kete rangan angka 1: jika tidak valid, angka 2: dapat dipertimbangkan, dan angka 3: jika valid. Data hasil validasi yang didapatkan akan diolah dengan model rasch yang menggunakan aplikasi minifacet.

\section{HASIL DAN PEMBAHASAN}

\section{Analisis Struktur Konten}

Analisis struktur konten terdiri dari beberapa tahapan yang dilakukan yaitu analisis kurikulum, analisis konten, dan analisis konteks. Tahap pertama yaitu analisis kurikulum pada materi sistem koloid mengacu pada silabus kimia kurikulum 2013. Pada tahap ini dilakukan penurunan Indikator Pencapaian Kompetensi (IPK) dari Komptensi Dasar (KD) dari materi sistem koloid. Dari hasil penurunan KD dihasilkan empat IPK pada materi sistem koloid yang akan dicapai. Selanjutnya pada tahap kedua yaitu analisis konten. Analisis konten pada materi sistem koloid merujuk pada beberapa buku kimia universitas yang dijadikan sebagai referensi. Beberapa buku yang digunakan diantaranya adalah (1). Chemistry The Molecular Nature of Matter karangan Jepersen, Brady, dan Hyslop, (2). Kimia Dasar 2 karangan Yayan Sunarya, dan (3). Kimia Dasar 2 karangan Syukri. Analisis konten yang dilakukan bertujuan untuk memper jelas konsep sains dan struktur konten berdasar kan pandangan para ahli. Oleh karena itu diperlukan adanya analisis konten. Pada tahap terakhir yaitu analisis konteks. Tujuan dari analisis konteks adalah untuk mengaplikasikan konteks pada materi sistem koloid dalam isu atau fenomena yang terjadi dalam kehidupan seharihari. Analisis konteks dilakukan dengan jurnal, artikel ilmiah dan buku kimia sebagai acuan.

\section{Investigasi Wawancara Peserta Didik}

Investigasi wawancara peserta didik bertujuan untuk mengetahui cara pandang peserta didik terhadap pemahaman konsep, menyelidiki minat dan sikap peserta didik terhadap materi sistem koloid. Tahapan ini dilakukan dengan berpedoman pada penelitian sebelumnya (terdapat pada beberapa artikel). Dari hasil investigasi yang diperoleh, peserta didik 
mengalami kesulitan dalam memahami materi sistem koloid terutama aplikasi sistem koloid dalam kehidupan sehari-hari. Hal tersebut disebabkan karena peserta didik cenderung menghafal konsep dan teori tanpa adanya pemahaman yang mendalam serta kurangnya keterlibatan lingkungan secara langsung dalam proses pembelajaran materi sistem koloid. Hal tersebut menyebabkan peserta didik tidak terlatih untuk menggunakan pemahaman mereka menge nai fenomena sains dan mencari solusi dari permasalahan tersebut secara ilmiah.

\section{Penyusunan Instrumen Tes}

Pada tahap ini, penyusunan instrument dibuat berdasarkan kisi-kisi soal dan aspek literasi yang menjadi pedoman penting dalam pembuatan soal. Hasil dari analisis kurikulum, analisis konten, analisis konteks, dan hasil investigasi wawancara peserta didik merupakan acuan dalam penyusunan kisi-kisi soal. Kisi-kisi soal terdiri dari KD, IPK, indikator soal, aspek literasi kimia (konten, konteks, HOLS, dan afektif), level kognitif dan level pengetahuan (berdasarkan taksonomi bloom), dan bentuk soal (essay).

Selanjutnya, pembentukan kartu soal konten, konteks, HOLS, dan afektif). Komponen yang terdapat dalam kartu soal adalah wacana soal, pertanyaan soal, dan rubrik penilaian. Dalam rubrik penilaian tercantum jawaban soal, level literasi kimia, dan skor jawaban.

\section{Validitas Konten oleh Subject Matter Expert}

Validitas konten (isi) dilakukan oleh lima orang validator (subject matter expert) yang terdiri dari 3 orang dosen jurusan kimia FMIPA Universitas Negeri Padang dan dua orang guru kimia SMA.

Instrumen literasi kimia pada materi sistem koloid ini terdiri atas 12 butir soal. Terdapat empat kelompok aspek dalam instrumen penilaian validitas konten pada soal literasi kimia yang mencakup (1) aspek materi/isi, (2) aspek bahasa, (3) aspek konstruksi, dan (4) aspek grafis dengan jumlah 13 sub aspek. Hasil penilaian dari validitas konten yang telah dilakukan merupakan pedoman dalam memperbaiki butir soal instrument yang masih kurang tepat. Hasil validitas konten dianalisis dengan model rasch yang menggunakan aplikasi minifacet

Hasil analisis data validitas konten oleh lima orang validator dapat dilihat dari Gambar 3. berdasarkan kisi-kisi soal dan aspek literasi kimia

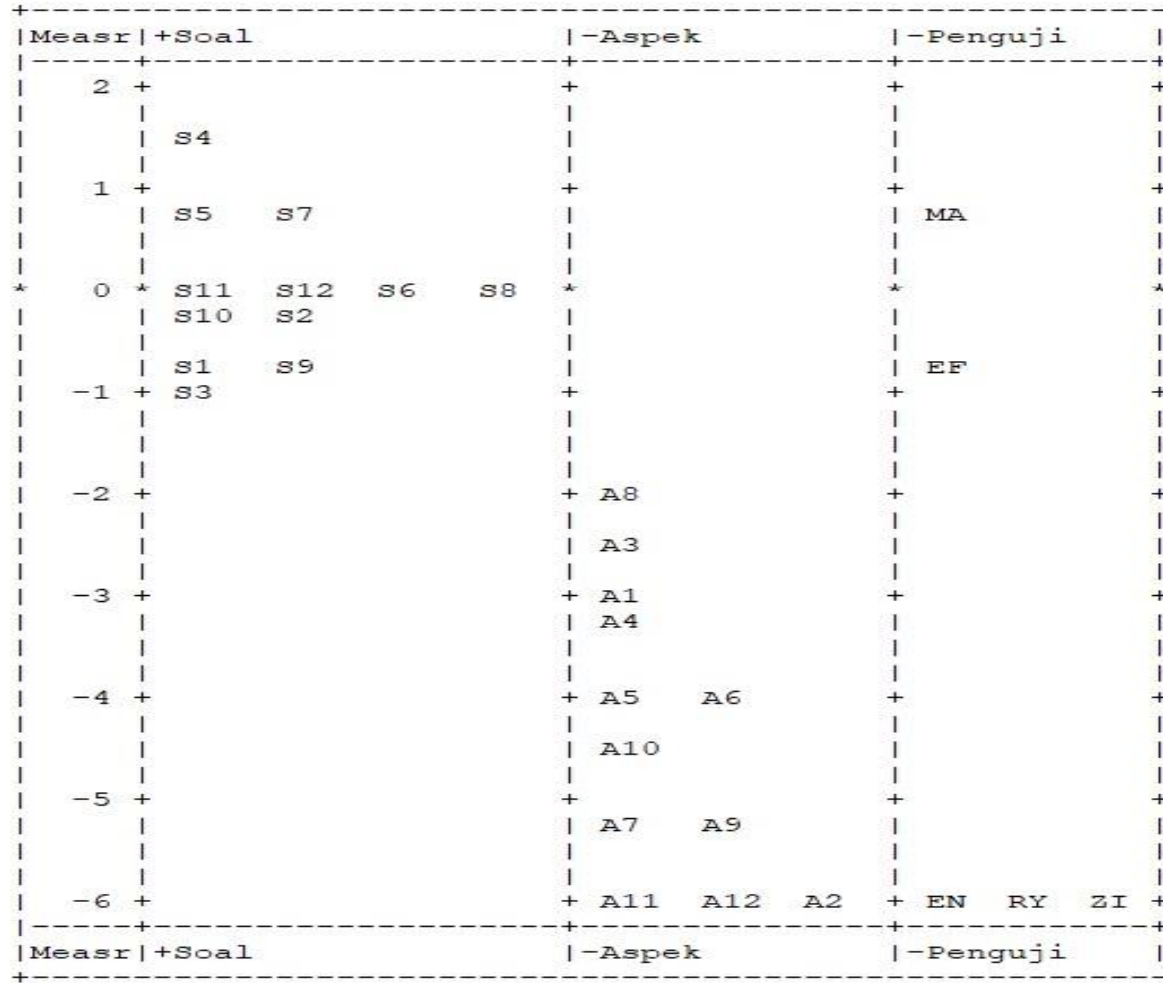

Gambar 3. Wright Map 
Gambar 3. merupakan penjabaran dari analisis validitas konten menggunakan aplikasi minifacet sehingga dapat dilihat hasil penilaian validator mengenai ketepatan butir soal dengan aspek penilaian instrument. Bagian kolom pertama pada gambar 1 disebut kolom measure yang mempunyai skala logit dengan rentang nilai -6 hingga +2 . Selanjutnya pada kolom kedua merupakan kolom soal yang menggambar kan kualitas soal berdasarkan penilaian validator. Kolom ketiga adalah kolom aspek penilaian instrument. Pada kolom ketiga, aspek yang memiliki posisi teratas merupakan aspek yang paling sukar dicapai atau aspek penilaian yang paling sukar dipenuhi dalam soal menurut validator sedangkan aspek yang berada pada posisi paling bawah merupakan aspek yang mudah dicapai atau aspek yang paling mudah dipenuhi dalam soal menurut penilaian validator. Pada kolom keempat merupakan bagian yang menggambarkan skema penilaian validator. Validator yang berada pada posisi paling atas merupakan validator yang sulit memberikan nilai sedangkan validator yang menempati posisi terbawah merupakan validator yang mudah dalam memberikan nilai.

Berdasarkan hasil analisis validitas konten menggunakan model rasch terhadap instrument soal literasi kimia pada materi sistem koloid yang berjumlah 12 soal dapat dijabarkan bahwa soal yang memiliki kualitas paling baik adalah soal nomor 4 berdasarkan penilaian validator. Pada bagian aspek penilaian, dapat dilihat bahwa posisi soal semua soal berada diatas aspek penilaian soal sehingga dapat dikatakan bahwa semua soal telah memenuhi aspek penilaian soal tersebut. Selain itu dapat dijelaskan bahwa aspek yang paling sukar untuk dipenuhi dalam soal adalah aspek nomor 8 (butir soal tidak bergantung pada jawaban soal sebelum dan sesudahnya). Selain itu, aspek yang mudah terpenuhi oleh semua soal adalah aspek nomor 2 , 11, dan 12 .

Tabel 1. Ringkasan Hasil Analisis Pengukuran Penguji Menggunakan Model Rasch

\begin{tabular}{cccc}
\hline $\begin{array}{c}\text { Strate } \\
\text { value }\end{array}$ & Reliabilitas & $\begin{array}{c}\text { Exact } \\
\text { aggreement }\end{array}$ & $\begin{array}{c}\text { Expected } \\
\text { Angreement }\end{array}$ \\
\hline
\end{tabular}

\begin{tabular}{llll}
\hline 3.1 & 0.80 & $88.9 \%$ & $89.6 \%$ \\
\hline
\end{tabular}

Dari data dalam Tabel 1. hasil pengukuran penguji menggunakan model rasch berupa nilai strata (Strate value), reliabilitas penguji, exact agreements, dan expected agreements. Nilai reliabilitas penguji menunjukkan kehandalan penguji atau validator dalam menilai instrument soal (Fahmina et al., 2019). Dari data dapat dilihat pada Tabel 1 bahwa nilai strata yang dihasilkan diatas 3 yaitu 3.1 yang menunjukkan bahwa penilaian penguji dapat dikatakan reliabel. Nilai reliabilitas penguji yang didapatkan adalah 0.80 yang termasuk dalam kategori baik. Selanjutnya nilai exact agreements (hasil persetujuan penguji) adalah $88.9 \%$, sedangkan nilai dari expected agreements (hasil perkiraaan persetujuan) adalah $89.6 \%$. Hal tersebut menunjukkan bahwa hasil penilaian validator atau penguji tidak jauh berbeda dengan hasil penilaian yang diharapkan. Berdasarkan peneltian yang telah dilakukan oleh fahmina (2019), instrumen tes dapat dikatakan valid apabila terdapat kesesuaian antara instrumen soal dengan materi dan kemampuan yang akan diukur. Instrumen tes dapat dikatakan sebagai instrumen tes yang baik apabila dapat memenuhi semua aspek penilaian instrumen tersebut (Fahmina et al., 2019). Dalam penelitian ini, dapat dilihat bahwa butir soal yang dikembang kan telah mampu memenuhi semua aspek penilaian soal dan memiliki hasil penilian validator yang tidakjauh berbeda dengan hasil penilian yang diharapkan sehingga butir soal literasi kimia yang telah dikembangkan dapat dikatakan valid memiliki kategori yang baik berdasarkan hasil penilaian validator.

\section{KESIMPULAN}

Berdasarkan penelitian yang dilakukan, instrument literasi kimia pada materi sistem koloid memiliki kategori valid dari segi konten dengan hasil persetujuan penguji (exact agree ments) yang diperoleh yaitu $88.9 \%$ dan hasil perkiraan persetujuan (expected agreements) sebesar $89.6 \%$. Hal tersebut menunjukkan bahwa hasil penilaian validator atau penguji tidak jauh berbeda dengan hasil penilaian yang diharapkan. 


\section{DAFTAR PUSTAKA}

Aisah, H., Yulianti Zaqiah, Q., \& Supiana, A. (2021). Implementasi Kebijakan Asesmen Kemampuan Minimum (AKM): Analisis Implementasi Kebijakan AKM. Jurnal Pendidikan Islam Al-Affan, 1(2), 128-135.

Afandi, Junanto, T., \& Afriani, R. (2016). Implementasi Digital-Age Literacy Dalam Pendidikan Abad 21 di Indonesia. Prosiding Seminar Nasional Pendidikan Sains, 2016-2113.

Arabbani, F. K., Mulyani, S., Mahardiani, L., \& Ariani, S. R. D. (2019). Analysis The Quality of Instrument for Measuring Chemical Literacy Abilities of High School Student Using Rasch Model. AIP Conference Proceedings, 2194(December).

Astuti, W. O., Zulyusri, \& Putri, H. D. (2017). Pengembangan Instrumen Asesmen Berbasis Literasi Sains pada Mata Pelajaran IPA Kelas VIII Semester II. Biosains, 1(2)

Bybee, R. W. (1997). Achieving Scientific Literacy: From Purposes to Practices. Portsmouth, NH, Heinemann Publishing.

Duit, H, G., U, K., M, K., \& Parchmann. (2012). The Modal of Educational Reconstruction A Framework for Improving Teaching and Learning Science Research and Practice In Europe.

Fahmina, Imansari, M., Sudarmin, \& Sumarni, W. (2018). Analisis Literasi Kimia Peserta Didik Melalui Pembelajaran Inkuiri Terbimbing Bermuatan Etnosains. Jurnal Inovasi Pendidikan Kimia, 12(2).

Fahmina, S. S., Masykuri, M., Ramadhani, D. G., \& Yamtinah, S. (2019). Content validity uses Rasch model on computerized testlet instrument to measure chemical literacy capabilities. AIP Conference Proceedings, 2194(December).

Firman, H. (2007). Analisis Literasi Sains Berdasarkan Hasil PISA Nasional Tahun 2006. Pusat Penilaian Pendidikan Balitbang Depdiknas.

Latisma, D. (2011). Evaluasi Pendidikan. UNP.

Matondang, Z. (2009). Validitas dan Reliabilitas Suatu Intrumen Penelitian. Applied Mechanics and Materials, 496-500(1),
$1510-1515$.

Mendikbud. (2020). Pusat Asesmen dan Pembelajaran Badan Penelitian dan Perbukuan Kementerian Pendidikan dan Kebudayaan AKM dan Implikasi pada Pembelajaran.

Muntholib, D., Mayangsari, J., Pratiwi, Y. N., Muchson, D., Joharmawan, R., Yahmin, D., \& Rahayu, S. (2018). Development of Simple Multiple-Choice Diagnostic Test of Acid-Base Concepts to Identify Studentsr Alternative Conceptions. 218(ICoMSE 2017).

Pakesa, C. M., \& Yusmaita, E. (2019). Perancangan Assesmen Literasi Kimia Pada Materi Laju Reaksi Kelas XI SMA/MA. Edukimia, 1(3), 84-89.

Rahardiana, G., Redjeki, T., \& Mulyani, S. (2015). Pengaruh Pembelajaran Contextual Teaching and Learning (CTL) Dilengkapi Lab Riil dan Virtuil Semester Genap SMA Negeri 1 Pulokulon Tahun Pelajaran 2013/2014. Jurnal Pendidikan Kimia (JPK), 4(1), 120-126.

Rahayu, S. (2017). Mengoptimalkan Aspek Literasi dalam Pembelajaran Kimia Abad 21. Prosiding Seminar Nasional Kimia UNY 2017, 21(4), 183-188

Rohim, D. C., Rahmawati;, S., \& Ganestri;, I. D. (2021). Konsep Asesmen Kompetensi Minimum Meningkatkan Kemampuan Literasi Numerasi Sekolah Dasar untuk Siswa. Jurnal Varidika, 33(1), 54-62.

Rusilowati, A. (2018). Asesmen Literasi Sains: Analisis Karakteristik Instrumen dan Kemampuan Siswa Menggunakan Teori Tes Modern Rasch Model. Prosiding Seminar Nasional Fisika Universitas Riau Ke-3, September, 2-15.

Sani, R. A. (2014). Pembelajaran Saintifik untuk Implementasi Kurikulum 2013. Trabajo Infantil, 53(9), 1689-1699.

Satya, \& Endang W. (2018). Development and Validation of an Integrated Assessment for Measuring Critical Thinking and Chemical Literacy in Chemical Equilibrium. International Journal of Instruction, 11(3), 557-572.

Shwartz, Y., Ben-Zvi, R., \& Hofstein, A. (2006). 
The Use of Scientific Literacy Taxonomy for Assessing The Development of Chemical Literacy Among High-School Students. Chemistry Education Research and Practice, 7(4), 203-225.

Son, A. L. (2019). Instrumentasi Kemampuan Pemecahan Masalah Matematis: Analisis Reliabilitas, Validitas, Tingkat Kesukaran Dan Daya Beda Butir Soal. Gema Wiralodra, 10(1), 41-52.

Sumintono, B., \& Widhiarso, W. (2014). Aplikasi Model Rasch Untuk Penelitian Ilmu-Ilmu Sosial.

Sutrisna, N. (2021). Analisis Kemampuan Literasi Sains Peserta Didik SMA di Kota Sungai Penuh. Jurnal Inovasi Penelitian, l(12), 2683.

Thummathong, R., \& Thathong, K. (2018).
Chemical Literacy Levels of Engi neering Students in Northeastern Thailand. Kasetsart Journal of Social Sciences, 39(3), 478-487.

Wijaya, E. Y., Sudjimat, D. A., \& Nyoto, A. (2016). Transformasi Pendidikan Abad 21 sebagai Tuntutan Pengembangan Sumber Daya Manusia di Era Global. Prosiding Seminar Nasional Pendidikan Matematika 2016, 1, 263-278.

Yuliati, Y. (2017). Literasi Sains dalam Pembelajaran IPA. 3(2), 274-282.

Yusmaita, E., \& Nasra, E. (2017). Perancangan Assesmen Literasi Kimia Dengan Menggunakan Model of Educational Rekonstruction (Mer) Pada Tema: "Air Sebagai Pelarut Universal." Jurnal Eksakta Pendidikan (JEP), l(2), 49. 